\title{
Guerrilla urbanism and digital production: a study of temporary occupation of public spaces
}

\section{SIGRADI2018 TECHNOPOLITICAS \\ xxii congresso da sociedade iberoamericana de gráfica digital 22th conference of the iberoamerican society of digital graphics 07|08|09|novembro|2018 iau usp | são carlos | sp br}

\author{
Igor Lacroix \\ UNB - University of Brasilia | Brazil | igorlacroix@gmail.com
}

\begin{abstract}
The paper presents some of the spatial production involved in three events promoted by different organizations in the city of Brasilia, Brazil. The role of architecture was to materialize sensations, experiences and phenomena for the people who participated. This production defines a kind of urbanism produced by groups of people who are temporarily using public spaces of the city with creativity. Limited by minimum time and budgets, and located in a place where high technology is scarce, handcraft is a necessity in all production processes. The main intention is to analyze how the use of advanced technology corresponds to this type of situation.
\end{abstract}

Keywords Parametric Design; Artistic Production; Ephemeral Architecture; Urban Intervention; Guerrilla Urbanism

\section{CONTEXTUALIZATION}

Some years ago, the government of Brasilia, the capital of Brazil, organized a legislation for the occupation of the city's public spaces, as part of a preservation plan known as PPCUB, 2012. Even before that, different groups of producers working with large-scale events already occupied different parts of the city to promote festivals, concerts and cultural events.

These producers visualized an opportunity to use the city in a creative way, also agitating the local economy, and possibly contributing to make it a better place. Actually, this kind of public space occupation, with events that bring culture, food, music and commerce to society, is helping turn Brasilia a city more alive, in relation to social interaction within its urban spaces (Frúgoli Jr., 1995).

Recognizing the potential of using ephemeral structures for scenography to such events, a collective known as Voxel Lab produced, between 2016 and 2017, a set of works that introduced in this context a differential factor for the use of technology, from conception to construction.

This paper will present three of these structures: the first, titled "The Mobile"; the second, a cardboard closure; the third, a multifunctional parklet. All works were the results of the empirical application of a phenomenological theory previously discussed to the work sessions that led to the understanding of urban intervention as an element of dialogue with the city.

\section{THE COLLECTIVE}

Voxel Lab is a group of architects that works on several work fronts, intersecting architecture and technology, from interior design to urban intervention. The organization of people within the collective is flexible. Specifically for the urban intervention work front, the team included a fixed core of five people in a total of ten involved in some of the processes that will be described.

During the working time of the three projects to be presented the team included professionals and students with training oriented to technical production, focusing on technological innovations. The type of work was collaborative, without hierarchies beyond the level of collaboration of each participant.

The work process of the team was the parametric design, even though the freehand drawing and modelling were instruments during creation stages. The team worked with the algorithmic modeling and rapid prototyping for the development and detailing of the projects, always with the intention of finding a generative system that would allow their evolution within pre-determined parameters. All designs were developed with Rhinoceros $\AA$ software and its plug-in Grasshopper $\AA$ in conjunction with diverse addons, such as Kangaroo $\AA$, Hoopsnake $\AA$, Lunchbox $\AA$, Weaverbird® etc.

\section{PHD RESEARCH PROGRAM}

Within the PhD research program of the Faculty of Architecture and Urbanism of the University of Brasilia UNB, in the last three years, it was developed an exploration of advanced technologies of design and construction in the Brazilian context. The objective was to recognize feasible application methods for contexts with low material resources.

During this period, it was dedicated to the application of parameterization and digital fabrication methods for the production of projects and architectural works. One of the results was the collaboration with Voxel Lab in the production of the set of ephemeral structures mentioned before, which was analyzed according to a line of 
investigation that focused on the observation of construction and execution processes from the perspective of digital fabrication.

The production of such structures have offered the possibility of verifying if it is possible to affirm a true digital fabrication practice, testing the limits of such practice. From this research, a question was considered regarding the local system of architectural production. The issue relates to the lack of availability of computer technology for more constructive processes, especially those technologies related to robotics.

\section{METHODOLOGICAL PROCEDURES}

The study begins with an experimental phase of parametric design application to solve real life construction problems. During approximately one year and a half, the team concentrated on producing different projects, for different situations. Systematically, we developed a simple approach towards every work: use as much innovative technology as possible to answer a building problem.

From this perspective, we used algorithmic modelling to conceive every work. Instead of the traditional plan / section representation, we used the computer to understand the building process. In this case, the twodimensional representation would not be enough to understand the complexity of the structures to be built. The three-dimensional visualization on the computer screen was essential.

Also from the same perspective, we kept the attempt to automate, as many constructive processes as possible, be it mechanized or digital fabrication. Therefore, the analysis differentiates the means of production during the whole process, searching for the real use of the computer in ordinary building actions.

After this period of production, all the works were analyzed through qualitative research, from the perspective of Stake (2003), because it considers the empirical processes of design and construction of the before mentioned structures as the main targets for knowledge reproduction. Therefore, the study concentrates on the analysis of how parametric design relates to the execution process, be it digital fabrication or handcraft.

The argument is that parametric design represents the construction process itself, as if the algorithm could demonstrate the specific building process through its functions. There are designs for robotic arms, and there are those for artisanal means of production.

As the line of research approached the construction aspects of the projects, so the paper emphasizes the description of these aspects. The in depth description of the design processes, or the algorithmic modelling, of the structures would better fit in another study. The maximum the description reaches is on how design adapts to construction processes, in order to orient them in a more efficient way.
The line of research was organized in two stages that begin with the investigation of the relationship between design and execution, than to the observation of the construction process itself. As the three structures are different by conception, so the steps of analysis varies from project to project, but always maintaining the logic that begins with parametric design and ends with a specific process of manufacturing.

\section{WORK IN THE ARTISTIC FIELD}

Before beginning the production of the projects, the group gathered for a series of readings and conversations about philosophy of art with the aim of leveling a common thought about the orientation of the works. When working with art, especially for a team made up of architects, the need arises for an adaptation with regard to the objectives and functions of the designed final space. In this case, it refers to a theoretical adaptation so that the team involved could produce from the conception of the projects, using a thought that could lead to the questioning of different stages of the most common architectural practice.

The readings followed two basic lines. The first one focused on some authors who thought phenomenology in relation to art and architecture (Heidegger, 2010; MerleauPonty, 1966; Pallasmaa, 2011). The second line followed two authors who helped guide a logic about technological production in art and architecture (Benjamin, 2012; Schumacher, 2011). Such readings served both to connect the collective in a thought that led the design process, and to awaken an artistic sense in the people involved, a direction for the artistic production.

The theme of phenomenology was very important for the orientation of the projects. From the beginning, there was already a thought about structures that could interact with the public, creating sensory experiences. The phenomenological theory responds to the sensorial question, and links art as one of the most accessible means of expression to the human being (Heidegger, 2010).

In his interpretation of Nietzsche's work, Heidegger (2010) presents the thesis that modernity lives the aesthetics of the artist. Instead of an objective aesthetic, that is based on the object, on the work of art itself, or a subjective aesthetic, anchored in the subject who perceives the work, the aesthetics of the artist is the one in which the producer himself expresses through his propositions. The producer of art, socially autonomous, no longer dependent on patronage, producing a speech with his own voice, is the entity who creates the artistic phenomenon.

Merleau-Ponty (1966) analyzes the artistic experience when he gives the example of Cézanne's production, which expressed traces of his psychology in his works. The painter represented the surrounding world associating aspects of his peculiar mind and not simply painting what he observed. The French artist has created a new experience for his viewers, distorting the apparent reality in new colors, forms and compositions.

The phenomenon of spatial perception is analyzed by Pallasmaa (2011), referring to an extended understanding of architecture, defining it as the art of connecting with the 
world through the senses. In this context, the essence of architectural propositions would be to establish sensorial relationships between the designed space and its users. The vision is no longer the main sense of spatial apprehension, mixing itself with the other senses, in a synaesthetic process.

Despite the restricted approach of only three authors who discussed phenomenology, the intention was to include a complete, and even chronological, reasoning on the subject. Starting from the understanding of the artist as a phenomenon of expression of his own experiences and sensations, then to analyze how the apprehension of the world occurs, not limited to the vision and connected to the psyche of the individual, to finally comprehend the way that phenomenology of spaces happens.

On the other hand, in approaching the question of production in art, it begins with the Marxist perspective, concentrating on the vision of Benjamin (2012), who criticizes the mere technical exploitation of tools that become popular in society. The banality of art occurs with technical reproducibility and the author places it through photography and film, that is, the photographic and cinematographic instruments.

In transposing such criticism to contemporaneity, there is an understanding that the computer is such an instrument whose indiscriminate use can lead to an empty practice and devoid of meanings. Schumacher (2011) proposes the computational use to reach the autopoiesis of architecture through what he defines as parametricism. Also aligned with Marxist thought, the author makes a sociological link to his proposition, from Luhman's theory, understanding architecture as a social system. In this sense, the possibility of parameterization of the space system composed by architecture arises according to behavior studies, movement flows and, for example, environmental comfort.

The difficulty that persists is to identify the limits of such self-constructed architecture, since to reach it one considers the use of advanced technologies. However, such technologies are generally inaccessible to loweconomy contexts, resulting in artisanal productions that occupy most of the construction process. With this, emerges an argument, on the extent to which it is possible to affirm such type of architectural production.

Conducting a critique of the indiscriminate use of technology is imperative in view of the economic conditions presented in the context. Technology cannot override design decisions and the feasibility of intended results and by itself is empty of sensations and sensory experience. Therefore, the use of computational processes can vary in quantity, depending on the type of material, and on quality, in accordance with the type of production process of the work.

\section{FIRST STRUCTURE: THE MOBILE}

After the theoretical readings that leveled the thinking of the collective in relation to the artistic work, some products of scenography were executed. The first one titled "The Mobile", produced by Fábio Sucupira Pedroza, with scenography direction by Lucas De Sordi. The Voxel Lab team met to make a structure that could be changeable, essentially mobile, to a local music festival. The proposed configuration consisted of slender aluminum bars, forming a flexible structural truss from the point of view of its assembly.

The main idea was to devise a transformable structure that could assume different characteristics throughout the days of the festival. Initially, a wireframe pyramid was built as a prototype, using six half-inch aluminum bars, each one meter long, interlocked with key rings. From this module, the team designed an algorithmic process in Grasshopper ${ }^{\circledR}$ to multiply these pyramids, always from one of the faces of the previous pyramid, in a process that created new ramifications, but that tended towards a nonuniform linearity.

The algorithmic model helped find the better shape for the structure, but mostly it provided a step-by-step way of assembly, through the simple visualization of the pyramids appearing one by one in front of a new triangular face, as we turned their functions on the definition board of Grasshopper®.

The cut of the aluminum bars was machined with a saw, considering the exact division of five bars in a total length of six meters, resulting in $1,20 \mathrm{~m}$ bars. Simply there were no other technology available for this process. In addition to the cut, the bars were drilled at their ends by a grinding machine installed in a vertical support. For that, the collective designed and $3 \mathrm{D}$ printed a piece to adapt the correct point for the hole in the grinding support, evenly leveling the position of all bars.

At the end, such a modular structure would be enveloped with plastic film, since it needed to create a surface that could receive mapped video projection, and instead of the key ring interconnections, a wire connection scheme was devised, both artisanal stages of the assembly process.

The collective considered making the connections with 3D printed nodes, but there was no budget or available deadline to print over fifty different pieces. Each node would require a connection system with the bars anyway, which would add financially and temporarily. Finally, it would also demand more precision for the processing of the bars, because in this case every millimeter would count for the fittings. Therefore, the wire connection scheme was the best solution by far.

The first opportunity to set up "The Mobile" structure was at the Dulcina de Moraes Faculty in the South Entertainment Sector of Brasilia, also known as CONIC. The first day of assembly was entirely within the college gallery, where the first sequences of pyramids were assembled from a three-dimensional map in the Rhinoceros ${ }^{\circledR}$ software. The map presented the distribution of the pyramidal modules from the step-bystep way of mounting described before.

The first day of assembly consisted of a lot of experimentation, considering an improvement of the process occurred during the execution. On that day, the first cut and pierced bars were assembled by interconnecting them with wire and then applying a layer of adhesive tape on each wire knot, with the intention of
3 
protecting the future plastic film envelope against possible traits.

The first sequences of mounted pyramids remained in the gallery until the first day of the festival, the second day of the assembly process. Three sequences were then removed from the gallery to a larger space, specifically the square in front of the entrance of the Dulcina de Morais Theater (Figure 1). There the sequences were connected to each other and already remained for exhibition and interaction with the public.

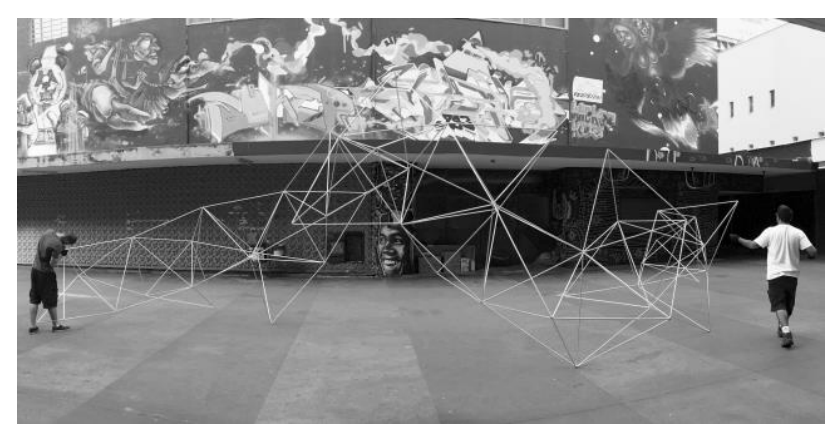

Figure 1: first assembly of "The Mobile" structure. Source: authors.

After the completion of this stage, which turned the three separate sequences into a single whole piece, the plastic film was applied, one of the most exhaustive and time consuming stages. The plastic film envelope was only finalized on the third day of assembly, second day of festival. On that day, dry ice was injected into the envelope and the piece was colored with LED stripes, creating an ambiance during the night (Figure 2). The idea was to broaden the sensory experience of the public, since "The Mobile" occupied the entrance space of the event, where the participants stayed before the concerts.

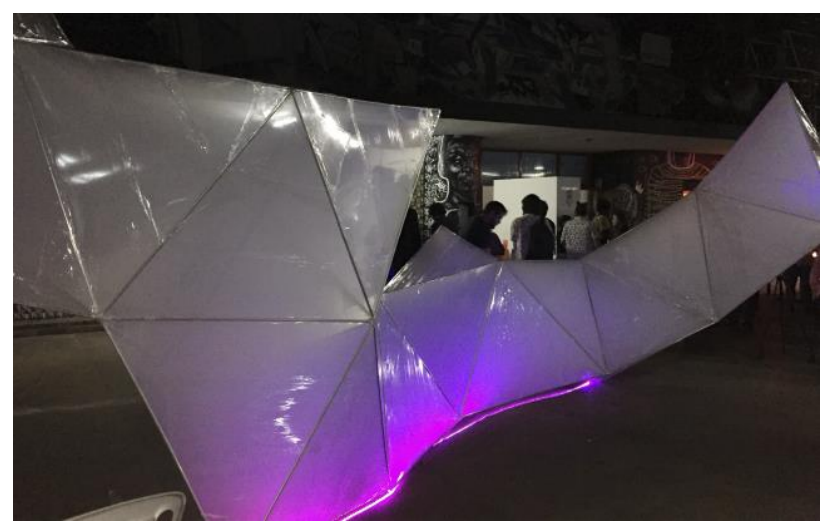

Figure 2: "The Mobile" enveloped with plastic film and filled with dry ice. Source: authors.

The fourth day of assembly was the simplest, because "The Mobile" was not part of the main set, since the theme of this third day of festival required other items that did not necessarily dialogue with the structure. In addition to that, a larger audience occupied the square and there was a need to free up more space for the concentration of people in front of the stage outside the theater. Therefore, the piece was located in a less accessible place, but still completely assembled and enveloped.

On the last day of the event, the fifth day of assembly, the team suspended the piece above the marquee at the entrance of the Dulcina de Morais Theater, where it would be positioned to receive the video mapping. To do so, the faces that would receive illumination were painted with acrylic white spray paint, thus leaving them opaque. The multimedia artist Lina Lopes produced the work of video projection.

The second opportunity to assemble "The Mobile", with basically the same properties of the first time, that is, a piece to receive video projection, took place inside the Centro Cultural Banco do Brasil - CCBB, in Brasilia (Figure 3). The piece was part of the scenography project of singer Criolo concert.

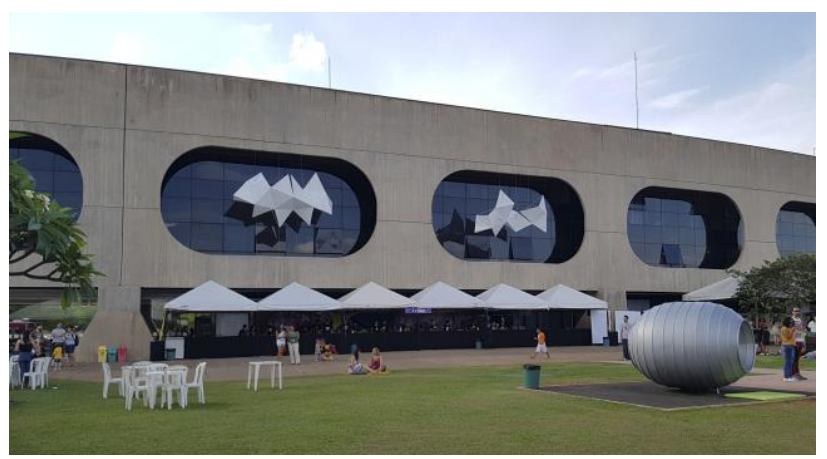

Figure 3: second assembly of "The Mobile" structure. Source: al thors

The procedure was practically the same, only three operations were different. First, the design was planned for two separate pieces with reduced sizes. Second, as there was only one day of event, the piece did not transform over its duration, applying the plastic film envelope only on the faces that would receive video projections, produced by Quase Cine Lab (Figure 4). Third, the pieces were designed for a fixation by steel cable rods that went down the facade of the CCBB building. This last process was not detailed previously and will not be detailed here, since it constituted another entirely artisanal stage that raised even more the assembly complexity and the time spent during execution.
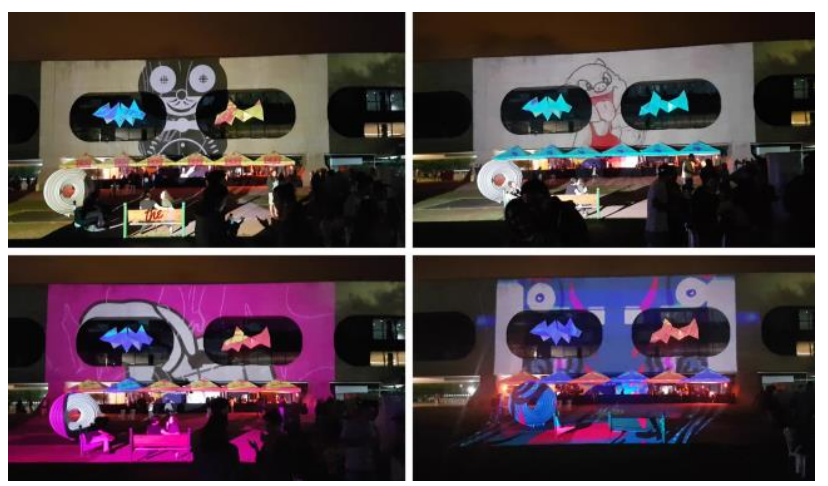

Figure 4: video projection at CCBB, Brasilia, Brazil. Source: al thors

From this second opportunity, we could affirm that the 3D printed nodes, that could connect each aluminum bar, would be a wrong decision, because this assembly way was different from the first one. Not only because of the two separate pieces, but also because the pyramid growing system resulted on different arrangements in the overall configuration of the modules. Thus, the nodes would not be effective in any way.

From the entire process of designing and building "The Mobile" structure, we understood that the presence of 
artisanal work is a constant in the production process even though the attempt of achieving the maximum automation. What we could do best was to rationalize handcraft through parametric design.

We also comprehended the presence of mechanized production throughout the whole process. Finally, we realized how little was the use of digital fabrication, only for the 3D printed piece which served to correct the drill points of the aluminum bars.

\section{SECOND STRUCTURE: CARDBOARD CLOSURE FOR DJ SPACE}

The second product of scenography, produced this time by the Picnik group, should work as a closure to protect the musicians' tent (Figure 5) of the event at the City Park of Brasilia. The main idea was to create a tropical ambiance, with a rustic aspect, that made up floral arrangements. The structure had to be quite functional, with basic fittings and simplified assembly. Therefore, a single $3 \mathrm{~mm}$ cardboard module was chosen to be the most efficient solution, with matching fittings for all boards.

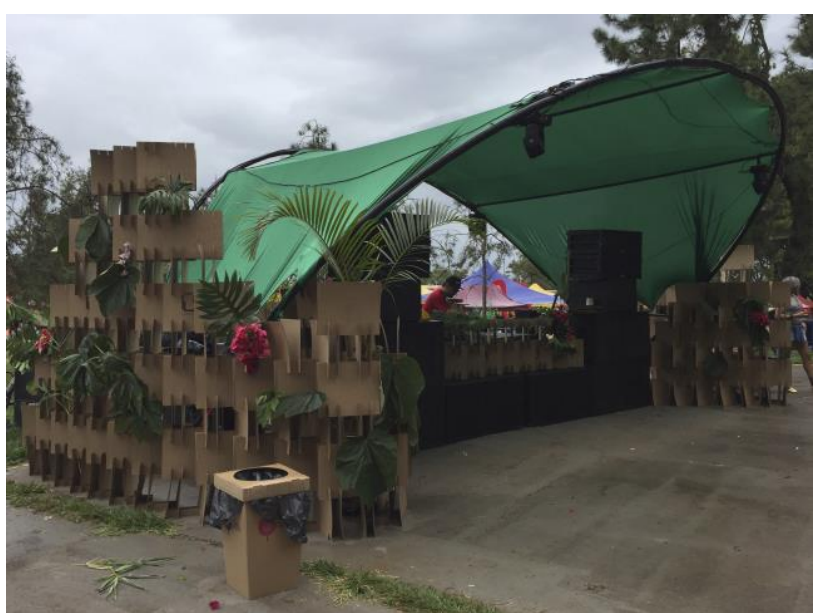

Figure 5: cardboard closure for Picnik event. Source: authors.

This work had a reduced time from conception to assembly, less than a week, and counted on many more mechanized steps during the manufacture, leaving only the handmade installation.

The algorithm of production of these modules, also conceived in Grasshopper $\AA$, besides providing, in an initial stage, a quick visualization of possible transformations to guarantee the best effect and functionality, also made possible, in the subsequent steps, the detailing of the modules, within a generative system. The result was the automatic generation of the final profile of the module from the aesthetic decision by the observation of the three-dimensional model on the computer screen.

A roller press knife cut in a single day 800 modules that were then packaged for shipping. Subsequently, a lasercutting machine to engrave and cut the event logo processed some of the boards, approximately 80 .

Once the plates delivered in place, the assembly process was fast and quite flexible. The fit of one module in the other was reinforced with double plates, creating greater resistance between the pieces. In a couple of hours all
800 pieces were assembled just so to test the overall effect of the closure. The Rhinoceros $\AA$ smartphone application was used to conference the shape during assembly.

The flexibility of the assembly process led to a diversity of composition. It became an interesting element of the work, being able to have freedom of the heights and sizes of each one of the 4 closures, two higher for the closing of the sides of the tent, one longer for the closure of the tent's back and one more decorative for the front closure of the DJ's desk. The applied vegetation gave the touch of finish to the work, bringing colors to the closing and a simple and attractive appearance, with flowers and tropical plants (Figure 6).
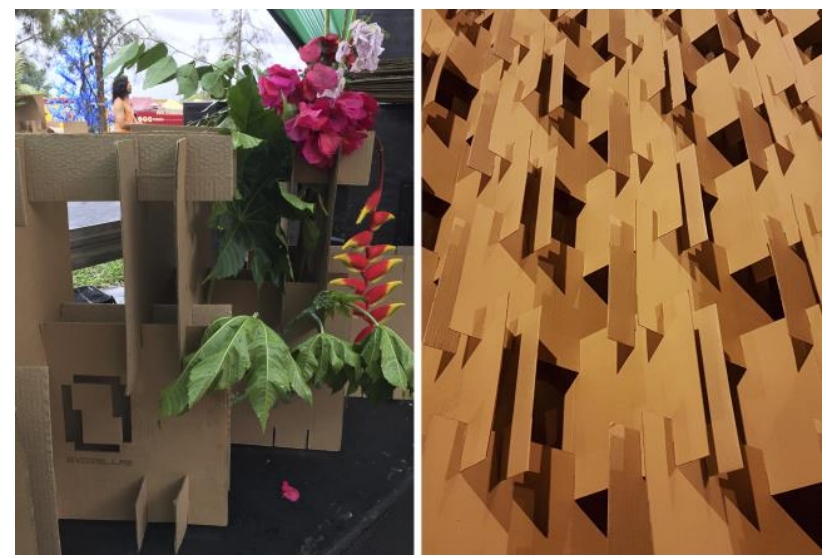

Figure 6: cardboard modules with event logo and flowers. Source: authors.

The difficulty of this project was the design and execution time in just 6 days. In this sense, the use of parameterization and mechanized and digital fabrication were essential for the viability of the final product. The parameterization facilitated the decision process of the final form of the closure, and without the mechanized manufacture, there would be no possibility of handmade production, hand cut of 800 pieces, apart from the precision of the cut, which directly affects the aesthetic quality of the product. In this way, it can be seen how the application of these computational and mechanical systems can facilitate the processes of designing, detailing and execution.

We learned from this project that even though we used machines to construct as many steps as possible, still we could not yet affirm an entire digital fabrication practice, because the computer was only used to engrave the Picnik Event logo on some of the cardboard plates. This project also revealed that we could achieve an entire digital production, at least for the material processing stage, because the cardboard could be laser-cut by Computer Numerical Control - CNC, but the cost and schedule would increase considerably.

\section{THIRD STRUCTURE: MULTIFUNCTIONAL PARKLET}

Produced by the Casa de Cultura da América Latina $\mathrm{CAL}$, under the direction of Alex Calheiros; belonging to the Dean of Extension - DEX, together with the Dean of Sports and Art - DEA, both of the University of Brasilia UnB, for the occasion of the "Tubo de Ensaios 2017" event entitled "Right to the city". The parklet configured a multifunctional space that occupied three vacancies in the 
public parking lot in front of the Anápolis Building, located in the Southern Commercial Sector - SCS, in Brasília, where CAL is headquartered.

The definition of parklet is found in article 2 of decree no. $55.045 / 14$, of the legislation of São Paulo, treating it as "an extension of the public walkway, accomplished through the implantation of a platform over the area previously occupied by the cantilevered bed of the public thoroughfare, equipped with benches, flower boxes, tables and chairs [...], with function of recreation or artistic manifestations."

An idea of creating a relation between the CAL building and its urban context guided the design of the parklet, and in that sense, it established a relationship between the facade of the building and the car lot located in front of it. The occupation was part of a political action of the CAL in relation to the right of use of public spaces and the momentary withdrawal of vehicles, returning such spaces to the population and creating new environments of coexistence (Figure 7).

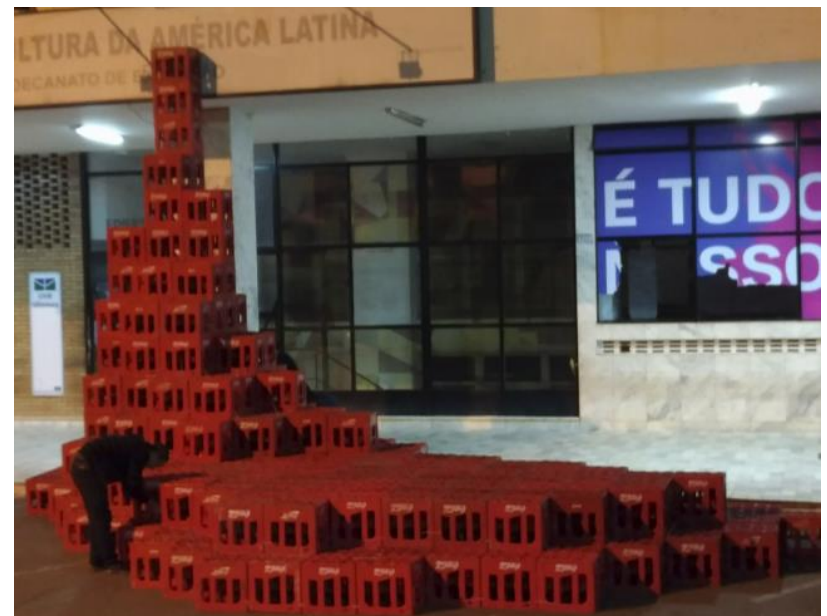

Figure 7: crate parklet in front of CAL's headquarter. Source: authors.

The project was carried out within a program of artistic residency of the $\mathrm{CAL}$, in partnership with artist Carla Barreto, and was presented in a workshop on urban intervention dedicated to the artists who would participate in the performance set of the event "Tubo de Ensaios" (Figure 8).

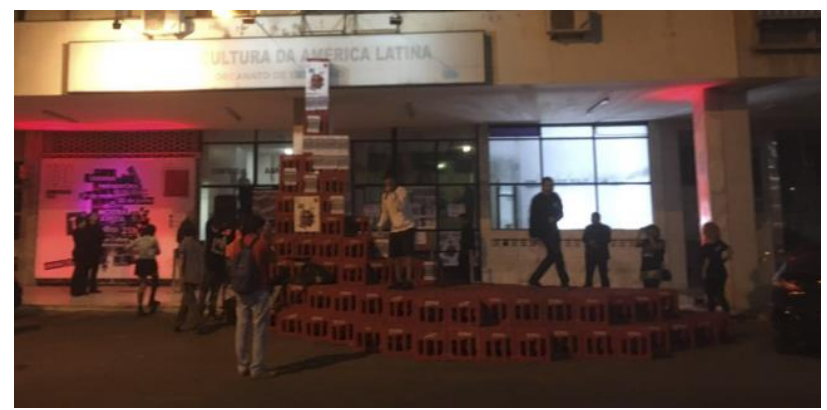

Figure 8: musical presentation at "Tubo de Ensaios" event. Source: authors.

A stacking of three hundred and fifty-two crates of soda, $31 \mathrm{~cm}$ wide, by $41,5 \mathrm{~cm}$ in length, by $36 \mathrm{~cm}$ in height, made the occupation of the parklet. The form of the stacking refers to an element that flows from the CAL's signage and accumulates on the floor, generating a stage for artistic presentations. The main reference to this draining effect was the sculpture in hand format, by Oscar Niemeyer, present in the Memorial of Latin America, in São Paulo.

The draining effect was generated from a Kangaroo $\AA$ simulation of a mesh, fixed by its central point at a specific location of the 3D model facade of the building, falling on an ameboid geometry elevated fifty centimeters of the floor, with the area required for the stage function, approximately fifteen square meters. The residual space under the resulting surface of the simulation was then filled with crates, reproducing its format in a voxelized manner, as if it lost resolution, but maintaining a general approximate form. An algorithm in Grasshopper® generated this entire process, easily achieving the draining shape, which would be quite complex to reproduce through point-to-point 3D modeling.

A three-dimensional map assisted the assembly process, distinguishing by color thirteen layers of stacking, from the broadest base, with a larger number of crates, to the top, with a single one. Map images were generated and shared in smartphone application for quick conference during assembly. Plastic tape ties of approximately four millimeters wide interconnected the crates. The higher area, creating a lookout, was reinforced with more ribbons, locking the crates vertically, in addition to horizontal locking.

As the material arrived ready-made at the assembly site, there was no processing to format it in a specific way. The only procedure was a piece-by-piece stacking done in a completely handcrafted process, guided by the threedimensional map. As the size and the final quantity of crates was only known until the day of delivery, then the algorithm facilitated the formal adaptation until the assembly day, and this was a very interesting aspect, making it possible to see how the algorithmic process adapts quickly to geometry from the specific parameters. Besides that, the form finding process through a computer simulation facilitated the aesthetic decision of the parklet, since it found a specific form that more accurately represented the original intention of the draining on the facade of the building.

This last project gave us perspective on the versatility of algorithmic modelling to present solutions for constructive problems. In a few minutes, right before assembly, the last decision was made for the final shape of the structure. Automatically generating the map to guide the building process. The only digital production involved was the rationalization of handcraft.

\section{DISCUSSION}

The role of these groups of producers dedicated to promoting social interaction in a creative way in the city of Brasilia is determinant for a new urban attitude, where the population can exercise its right to the city. Hou (2010) defines as guerrilla urbanism this type of action, where citizens themselves find "opportunities in the existing urban conditions for [...] changes against the dominant forces in society." The decision to orient the work within an aesthetic of the artist considers this, in an attempt to express the experiences and sensations that such groups propose for the population. 
Throughout recent research, the work of Caldwell (2016) emerged as a synthesis of the guerrilla urbanism associated with digital production argument that this paper presents. The work of QUT Design Lab is remarkable in the way they mix humanities and technology, understanding contemporaneity beyond the lens of technique.

All the examples analyzed here serve to demonstrate the relationships between the uses of computational processes, from design to execution, with an artistic production, oriented to the occupation of public spaces. The main reference for this type of occupation is the work of Peixoto $(1996,2012)$ which is considered here a synthesis of what was approached as a theory of art to guide the works. Firstly, with regard to the question of phenomenology, of the connection between the individual and the spaces around him, the understanding of the flanéur, as the actor who experiences the city. Then, in relation to the interdisciplinary approach proposed by the Arte Cidade program where architectural work mixes with artistic work, to create spaces that could requalify large urban areas.

The exploration of alternative constructive processes, in search of new types of space and housing, as an academic research topic, is not a new course in Brazil. The NOMADS group of USP is a reference that cannot fail to be mentioned. The work of Tramontano (2000) on experimental housing solutions, using constructive techniques different from traditional civil construction systems, reveals the importance of thinking beyond the most commonly used production scope, due to an economic component that is indispensable within the architectural processes.

One of the consequences of this is the study of the flexibility that alternative construction systems can provide, guiding viable solutions to various situations of occupation of public or private spaces. NOMADS itself explores such issues from the standpoint of the methodology of parametric design and digital fabrication. Tramontano (2015) presents a teaching methodology that explores such a design process, working with complex geometries and taking into account computer-controlled manufacturing.

The study on new types of space and housing is not limited to architectural space; it also reaches the artistic field, since much of the contemporary artistic production explores precisely the participants' sensory experience and the relations between body and space. Krauss (1984) defines sculpture in an extended field intertwining it with landscape and architecture, seeking a conceptualization that includes new artistic fields, such as land art, installation etc.

The need for a theory of art is indispensable here, since to maintain the quality of production, working within the artistic field, it takes more than technique, or technological application, but artistic awareness and operation. Working with contemporary art requires more than technological innovation, requires conceptual exploration, feelings and sensations, poetry, imagery. On the subject, Benjamin (2012) presents a valid theory within the field of aesthetic philosophy, almost an alert, about the use of the technological apparatus for artistic production.

It is exploring this interstice of space produced for art through sensory experiences that this article fits. What epitomizes these elements is the ephemeral architecture, which is characterized by rapid assembly and disassembly processes, and transportation logistics. The cases presented exemplify such production techniques, demonstrating the presence from artisanal processes of manufacturing and assembly to more automated processes.

\section{FINAL CONSIDERATIONS}

It is considered that the use of computational techniques, namely parametric design and digital fabrication, is very helpful for the application in these types of situations, where resources are usually scarce and deadlines are short. Such techniques enable agility while ensuring the quality of work. However, there is still a gap between what is designed parametrically and what is possible to be built with the help of the computer, in the Brazilian context.

One characteristic was common to every project, the material chosen for the structure dictated all constructive decisions, and the algorithms followed those decisions. As if, they were formulated to express the ways of processing the materials. Unfortunately, the lack of resources constraints the production itself, then even simple decisions into the automation direction, should be adapted to the economic aspect of the project.

Another similar characteristic was the modularity of each project, or the voxelization of the materials. The projects were selected purposely to express this brand of the collective: to work with voxels, or 3D pixels, for the configuration of the structures.

The first project was complex, involved much more production stages, which made it difficult to introduce innovative technologies, especially when working with low budgets. Because for every design decision there is an economic problem associated. If "The Mobile" was supposed to be a singular sculptural piece, assembled in a specific way, then the $3 \mathrm{D}$ printed knots would work efficiently. And maybe we could figure out another enveloping system cut by CNC methods, instead of the plastic film handcrafted way. But for every of those decisions, the production time, the financial aspect and even the final weight of the structure would increase proportionally.

The second and third projects were simpler. We tried to simplify production by reducing the material processing stages, until the last project did not involve any processing, just design and direct assembly.

What could be verified, from the fabrication point of view of all three structures, were parametrized processes rationalizing the striking presence of artisanal production. Even if the parameterization is ideal for the control, for example, of a robotic industrial arm, there is simply no access to such machinery. Parameterization understood, in this sense, as the way to control the operational methods of such technologies, but currently there are no viable construction applications in the context. 
The autopoiesis of architecture proposed by Schumacher (2011) is still unattainable in certain contexts, keeping the logic of artisanal production present in all stages of the construction process. Even though the examples presented here are extremely simple and small in relation to the work of the great masters, it was intended in all of them to achieve maximum automation at all stages. However, what prevailed was a type of rudimentary production rationalized by a computational design.

Regarding the issue of artistic production, what is pointed out is the need to fill certain gaps left by technological production by a theory of support that allows a less limited productive linkage by techniques, or productive processes, and that maintains more relation with the poetic, with the imagination. Shusterman (2003) builds a reasoning relationship between philosophy and art, and argues that philosophy alone is insufficient and incapable of bringing art into closer integration with life, but that it can provide inspirations and fundamental arguments for the transformation of art. There is an agreement with the author when he proposes philosophical reasoning as an instrument of criticism and consideration of what is actually produced, considering production beyond its technical, operational and productive results. Without this kind of thinking, technologically made products are meaningless, especially when one thinks of a work of art.

This article does not intend to deepen a study on aesthetics and its relation with technology, but it is evident the need to establish a rationale applicable to the productive fields of architecture and design, when the final objective is the artistic work. The main goal here is to affirm a sustainable architectural practice by means of an alternative production, which mixes artistic practice and digital production, and which is capable of supplying the same demand, with the same quality, in terms of finished product.

The experiments, in the field of what is considered ephemeral architecture, prove the possibilities and limits of the use of diverse materials, in general with limited use within the daily living spaces. Mass production sometimes hides processes that can be as efficient as those traditionally used, and more economically and socially interesting. Customization makes it possible to achieve specific spatial experiences that can be as attractive and durable as commercially available design pieces.

Computational techniques operationalized the mentioned experiences considering the local limitations in the productive scope. Therefore, a projective practice was oriented to allow the execution of complex procedures and that in fact constituted a series of other technical necessities besides what the most common materials require. Here the critique of the article is established, characterizing the limitations of the digital production and perceiving the real dimension of the use of the computational processes within a scale of production quite artisanal. The argument that is set, therefore, is how little is the use of digital fabrication, even when striving to increase automation of the most diverse stages, from design to execution, due to the context limitations.

\section{ACKNOWLEDGMENTS}

We thank to the Voxel Lab collective composed by Felipe Sanches, Filipe Fuentes, Gabriel Lago, Guilherme Rabelo, Guilherme Santoucy, João Paulo de Castro and Marco Maron. Without your hard work and commitment, none of this would be possible.

\section{REFERENCES}

Benjamin, W. (2012). A obra de arte na era de sua reprodutibilidade técnica. In Magia e técnica, arte e política: ensaios sobre literature e história da cultura. Translation: Sérgio Paulo Rouanet. São Paulo: Brasiliense.

Caldwell, G. A. \& Guaralda, M. (2016). Blurring the physical boundaries of the city: Media architecture and urban informatics for community engagement. In G. A. Caldwell, C. H. Smith \& E. M. Clift (Eds.). Digital futures and the city of today: new technologies and physical spaces (pp. 235-250). Bristol: Intellect Ltd.

Frúgoli Jr., H. (1995). São Paulo: espaços públicos e interação social. São Paulo: Marco Zero.

Heidegger, M. (2010). Nietzsche, Volume I. Translation: Marco Antônio Casanova. Rio de Janeiro: Forense Universitária.

Hou, J. (2010). Insurgent public spaces: guerrilla urbanism and the remaking of contemporary cities. New York: Routledge.

Krauss, R. (1984). A escultura no campo ampliado. Translation: Elizabeth Carbone Baez. In Gávea, n. 1. Rio de Janeiro: PUC.

Merleau-Ponty, M. (1966). Sens et non-sens. Paris: Les Éditions Nagel.

Pallasmaa, J. (2011). Os olhos da pele: a arquitetura e os sentidos. Translation: Alexandre Salvaterra. Porto Alegre: Bookman.

Peixoto, N. B. (1996). Paisagens urbanas. São Paulo: Editora SENAC.

Peixoto, N. B. (2012). Intervenções urbanas: Arte Cidade. São Paulo: Editora SENAC.

Schumacher, P. (2011). The autopoiesis of architecture, Volume 1: a new framework for architecture. Chichester: John Wiley \& Sons.

Shusterman, R. (2003). Transformando a arte e a filosofia. Translation: Neusa da Silva Matte \& Maria Ozomar R. Squeff. In: Zielinsky, Mônica (Org.). Fronteiras: arte, críticas e outros ensaios. Porto Alegre: Editora UFRGS.

Stake, R. E. (2003). Case studies. In N. K. Denzin \& Y. S. Lincoln (Eds.). Strategies of qualitative inquiry (pp. 134-164). Thousand Oaks: SAGE Publications.

Tramontano, M. (2000). Unidades experimentais de habitação. In Projeto Design, ed. 243. São Paulo: Arco Editorial.

Tramontano, M. (2015). When research and teaching connect: parametric design, digital fabrication and architectural design. Proceedings of the $29^{\text {th }}$ Annual Conference of the SIGraDi. Florianópolis: November 23-27. 